\title{
STUDENTS' PREPAREDNESS TOWARDS WRITING A BACHELOR THESIS; A SURVEY-BASED INVESTIGATION
}

\author{
Anette HEIMDAL ${ }^{1}$, Paul R. SVENNEVIG ${ }^{1}$ and Thomas G. NORHEIM ${ }^{2}$ \\ ${ }^{1}$ University of Agder \\ ${ }^{2}$ Dagfin Skaar
}

\begin{abstract}
This paper investigates how students perceive their preparedness when they start writing their bachelor thesis. Students at the University of Agder (UiA) will, in their first semester, receive lectures in ethics, academic writing and referencing to equip them for future writing, mostly academic reports. In the Civil Engineering Department, an IMRAD report template is used during their bachelor thesis. The Civil Engineering Department also requires lecturers to use variations of the same template for every report to prepare the students for their bachelor thesis. This paper will use this year's bachelor students as a case study.

In January and February, the students attended a workshop and followed a course titled "TFL200 system course for engineers". The workshop gave the students a recapitulation in academic writing, referencing, the writing process, project management, and how the template is structured, explaining the template's different parts. TFL200 covered ethics, systems theory, innovation and LCA, sustainability, and academic writing.

In the spring semester, two surveys were sent out to third-year bachelor students in Civil Engineering writing their bachelor thesis. The first survey was sent out at the beginning of January, before the students started their course and workshop. This survey investigated to which degree the students feel prepared, motivated, and ready to write their bachelor thesis. The second survey was conducted in late February to evaluate the effects of TFL200 regarding the bachelor project and the workshop, measuring the student's current preparedness, motivation, and to which degree the students feel competent.
\end{abstract}

Keywords: Survey, civil engineering education, students, peer review, supervision, academic writing, motivation

\section{INTRODUCTION}

According to Imel [1] the way of learning how to work in groups is by working in groups. However, working in groups on a project can be challenging. In Burdett's study [2] the students experienced that working in groups was particularly challenging when projects were graded. They were concerned that some students would end up doing all the work to achieve good grades, while other group members got a "free ride" by not participating. Even so, the results of Burdett's study show that the students gained competencies. A clear majority said that they learned to negotiate with other group members, manage tasks effectively, share responsibility, solve complex problems, resolve conflicts, and develop a shared vision for the group.

Several analyses [3-5] have confirmed that feedback to students is essential for the learning outcome. During the students' bachelor thesis, this is provided through supervision. Each group will be assigned a supervisor from the university, who is competent within the subject of the students' bachelor thesis. The students' expectations do not always match reality. It is therefore, according to Lovitts [6], important to clarify the expectations regarding the supervision early in the process. Even when this is clarified there can still be some challenges in supervision. Lundgren and Halvarsson [7] discovered that students worried about their supervisors' competence with the written structure of a thesis. Since the Civil Engineering Department at the University of Agder requires the students to use an IMRAD-like template many of the supervisors do not necessarily have the required competence. Hence, we have tried to solve this by organizing workshops and peer reviews. During the workshops and peer reviews the 
supervisors who were present knew the template and formalities regarding writing a bachelor thesis. By having these workshops and peer reviews, the students have an extra arena where they get supervision. As stated by Mulder et al. [8] and Gielen et al. [9] there are several benefits in using peer review in higher education. One being that the students get better at evaluating their own work. In addition, the quality of the written work can increase.

National Guidelines for engineering studies [10] require students to have general competencies in environmental, social, health-related, and financial consequences around their work in Civil Engineering and put this into an ethical and life cycle perspective. They also require the students to know how to work in groups, to be able to write academically and to do credible research. When the students have studied for two and a half years, they start their final project: their bachelor thesis. This is where they can showcase their skills learned throughout their studies. So, how prepared are the students when their final semester starts?

\section{CASE}

To identify the students' preparedness towards writing a bachelor thesis, this year's third-year civil engineering bachelor students were used as a case study. These students originally started their bachelor's degree in 2018 and will finish in the spring of 2021. This class consists of 62 students. When students write their bachelor thesis at the University of Agder they must work in groups varying from 2-4 individuals. Parallel to writing their thesis, the students participate in the mandatory course titled "TFL200 - system course for engineers". The course covers ethics, systems theory, innovation and LCA, sustainability, and academic writing. The final semester thus consists of 30 credits; 10 awarded for TFL 200 and 20 for the bachelor thesis.

We were interested in the students' competencies concerning the report template, the subject of their thesis, academic writing, referencing, motivation, planning a project, supervision, and group dynamic, both before starting their final semester and after having the TFL200 course for almost two months. The study programme tries its best to prepare the students towards writing their bachelor thesis. Hence, the students must work in groups from the very beginning of their study. They will have a minimum of one group project every semester and will hopefully learn some group dynamics. That students learn to work in groups is also an important part of the National Guidelines for engineering studies [10]. In one subject the students also learn how to use a progress plan to plan a project, which is required to be used during their bachelor thesis. The students have also had several exams consisting of reports, where academic writing is a part of the grading. Supervision is the only topic investigated in this paper which the students have not experienced prior to writing their bachelor thesis.

In their final semester the students started the $6^{\text {th }}$ January. We arranged a workshop for the students on the $8^{\text {th }}$ January where we gave the students a recapitulation in academic writing, referencing, the writing process, project management, and how the template is structured, explaining the template's different parts. In the Civil Engineering Department, the students must use an IMRAD report template for their bachelor thesis. This is the same template they have used previously in the study programme, which means that the students will most likely recognize the structure. Even though the TFL200 course covers academic writing in general, the students were given an extra lecture on the $28^{\text {th }}$ January which emphasized academic writing specifically for the bachelor thesis. In this lecture the students also learned about referencing and information evaluation. Part of the mandatory requirements for submitting the bachelor thesis are that students must deliver their research question and a progress plan before the $5^{\text {th }}$ February. Therefore, a voluntary peer review was held on the $3^{\text {rd }}$ February. We have had great experience with peer reviews [11] previously, so we decided to arrange it equally. This means that the peer review consisted of a 10-minute presentation and 5 minutes of feedback from peers. All the groups had another group as opponent that had prepared a feedback in advance. The peer review was arranged digitally because of Covid-19.

\section{METHOD}

This paper is based on the feedback from the bachelor students through two surveys. The surveys were distributed on two different occasions in the final semester of their bachelor's degree. The scope of the surveys was to identify the students' preparedness towards writing their bachelor thesis. The questions did not differ much from the first survey to the second survey, mainly the tense of the verb. This was done to identify if there was any difference after almost two months of writing their bachelor thesis. In 
addition, the students who participated in the peer review were asked to rate the peer review process before the session ended.

The first survey was distributed to the bachelor students at the start of their final semester; the $6^{\text {th }}$ January. This survey was available for the students to answer for two weeks. The second survey was distributed on the $22^{\text {nd }}$ February and was only available for three days. The surveys were made using the survey tool SurveyXact and distributed through the learning platform Canvas. The first survey contained 15 questions and the second survey contained 14 questions. The questions were designed with a scale from 1 to 5. Depending on the question, 1 meant "not prepared", "very poorly", "not motivated" and 5 meant "very prepared", "very good" or "very motivated" for example. To measure the students' preparedness the following subjects have been focused on; the report template, the student's knowledge about the subject of their thesis, academic writing, referencing, motivation, planning a project, supervision, and group dynamic.

The results were analysed by calculating an average from the ratings in the surveys, and a standard deviation to show the variation in the results. This was not done on the questions that did not contain a 1 to 5 answer option.

The timeline between the two surveys is illustrated in Figure 1. The figure illustrates what the students received of arranged guidance between the surveys. Their supervision has also started in this period.

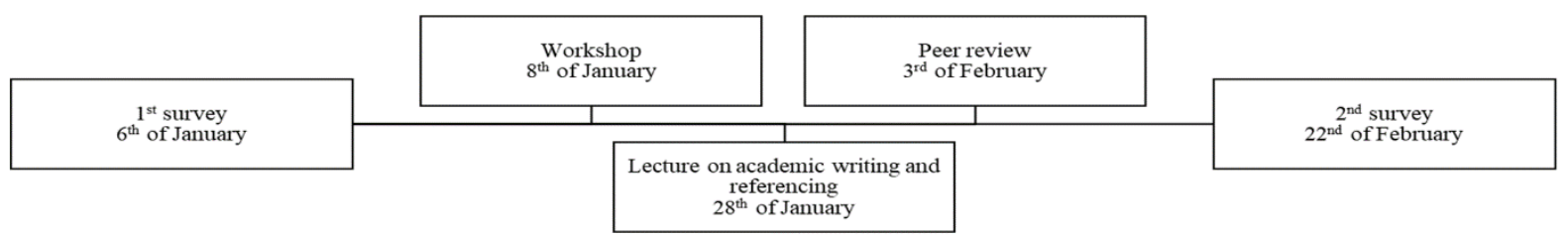

Figure 1. Timeline between the two surveys

\section{RESULTS AND DISCUSSION}

An overview of the distribution date, number of questions and response rate to each survey is shown in Table 1 below. The first was sent out before the students had started doing their bachelor thesis, and the second when we believe the students knew what was expected of them in a bachelor thesis. This way we could ask almost the same questions but on a different time in their course of study. We could therefore see if what they thought in the beginning matches the reality.

Table 1. Information about the surveys

\begin{tabular}{llll}
\hline & Date & No. of questions & Response rate \\
\hline Survey 1 & 6-Jan-21 & 15 & $64.5 \%$ \\
Survey 2 & 22-Feb-21 & 14 & $48.4 \%$ \\
\hline
\end{tabular}

The results from the surveys are shown in Table 2. The score is a calculated average from where the students could rate the answer from 1 to $5-5$ being the highest and best score. The results indicate very little difference from the first survey to the second. The three points that stand out are 1,9 and 10 . Understanding the report template had improved from 4.05 to 4.30 . So, although $85 \%$ of the respondents recognized using the report template previously in their study, they gained some more knowledge about the template after the workshop and working with it. Point 9 and 10 regard supervision, which is new to the students. They have little or no knowledge about supervision from their study before starting their final semester. Perhaps surprisingly, the students report that they receive more assistance from their supervisor than what they thought in the start. The students have experienced peer review at least on one occasion in their study. However, we can see that the expected assistance and benefit from supervision and peer review was lower than what they received. Since the peer review was voluntary, only 17 of the 62 students participated in the process. The participants were asked to rate the benefits from the review. 12 of these students answered and rated the peer review process to an average of 4.0. It is therefore strange that the overall rating of the peer review turned out to be 3.07 when there was a possibility to answer, "was not present". Nevertheless, it indicates that the workshop and peer review 
are beneficial for the students. This matches the findings from last year [11], where the students scored the peer review process high but also had high expectations to the process.

Table 2. Results from the surveys

\begin{tabular}{|c|c|c|c|c|c|}
\hline & & \multicolumn{2}{|c|}{ Survey 1} & \multicolumn{2}{|c|}{ Survey 2} \\
\hline & & $\begin{array}{c}\text { Average } \\
\text { score }\end{array}$ & $\begin{array}{l}\text { Standard } \\
\text { deviation }\end{array}$ & $\begin{array}{l}\text { Average } \\
\text { score }\end{array}$ & $\begin{array}{r}\text { Standard } \\
\text { deviation }\end{array}$ \\
\hline \multicolumn{6}{|c|}{ Report template } \\
\hline \multirow[t]{2}{*}{1} & Understanding the report template & 4.05 & 0.72 & 4.30 & 0.79 \\
\hline & Student's knowledge & & & & \\
\hline 2 & Student's knowledge about the subject of their thesis & 4.03 & 0.72 & 3.80 & 1.06 \\
\hline \multirow[t]{2}{*}{3} & Obtain new knowledge & 3.89 & 0.75 & 3.87 & 0.68 \\
\hline & Academic writing & & & & \\
\hline \multirow[t]{2}{*}{4} & Master writing academically & 3.68 & 1.02 & 3.83 & 0.99 \\
\hline & Referencing & & & & \\
\hline \multirow[t]{2}{*}{5} & Master referencing and information evaluation & 3.76 & 1.08 & 3.73 & 1.01 \\
\hline & Motivation & & & & \\
\hline \multirow[t]{2}{*}{6} & Motivated to write a bachelor thesis & 4.39 & 0.95 & 4.37 & 0.96 \\
\hline & Planning a project & & & & \\
\hline 7 & Ability to plan projects & 3.81 & 0.89 & 3.75 & 1.00 \\
\hline \multirow[t]{2}{*}{8} & Punctuality & 4.61 & 0.68 & 4.60 & 0.77 \\
\hline & Supervision & & & & \\
\hline 9 & Assistance from supervisor & 3.66 & 0.75 & 4.07 & 0.83 \\
\hline \multirow[t]{2}{*}{10} & Benefit from peer review & 2.89 & 1.55 & 3.07 & 1.71 \\
\hline & Group dynamic & & & & \\
\hline 11 & Ability to cooperate & 4.57 & 0.69 & 4.30 & 0.99 \\
\hline 12 & Use of previous experience & 4.32 & 0.74 & 4.14 & 0.92 \\
\hline
\end{tabular}

The question regarding if the students master to write academically increased slightly. This could mean that the lecture on academic writing had a small effect or that the students already had the required skills and knowledge. 3.68 and 3.83 still mean that it is possible to improve. The same applies to referencing with an average score of 3.76 and 3.73. According to Almlie [12], who is the actual lecturer in academic writing both in TFL200 and the lecture on the $28^{\text {th }}$ of January, there needs to be a higher focus on writing in engineering studies. Almlie concludes that learning to write academically is a process, not something you learn after a few lectures or workshops. Hence, the grading on all reports during the students' study programme take this into account. In Almlie's study, $74 \%$ of the students wrote that they frequently or always use the feedback to improve future performance. However, the results in this investigation show that there is still more we can do to improve the students' skills in academic writing.

The requirements when writing a bachelor thesis is that the students work in groups and deliver a progress plan in the beginning of February. The ratings from the first survey and the second survey on "Ability to plan projects" and "Punctuality" does not differ. This also applies to the questions regarding group dynamic. Some students have previous experience on planning a project with the same planning programme (Microsoft Project) that is used during their bachelor thesis, but all the students have experience on working in groups in projects. The average score on ability to cooperate is 4.57 with a very low standard deviation on the first survey, indicating that this is something the student's master. Since the average score on the second survey is 4.30 it indicates that the requirements about teamwork skills in the National Guidelines for engineering studies [10] is met. The reason can be explained with the findings of Imel [1] - simply working in groups makes the students better at working in groups. The result indicate that this is something the students also recognize since the score on the use of previous experience from working in groups had an average of 4.32 in the first survey, and 4.14 in the second survey. Even though the students participating in Burdett's study [2] were concerned about team members not participating, this does not seem to be the case here because of the high scores on group dynamic and punctuality. 
The motivation scores high on both surveys with an average on 4.39 on the first survey and 4.37 on the second survey - both with a low standard deviation. Hattie and Jaeger [4] concludes that the teachers have a significant role in the students' learning outcome. During the students' bachelor thesis, they must use their knowledge and experiences from previously in their study and must obtain new knowledge mainly alone. They do however have supervision. According to the survey, $73.3 \%$ of the students have supervision once a week, whereas the rest have supervision biweekly. This means that the students get constant feedback during their bachelor project. Based on Almlie's study [12] 64\% said that the feedback frequently or always motivates in their study, and $22 \%$ said that the feedback occasionally motivates. This can be a reason for the high score on the students' motivation. The students also answered what grade they were working towards and $90 \%$ said an A or a B in the first survey, and $87 \%$ still hoped for the same in the second survey. This can also be an indication of high motivation.

\section{CONCLUSIONS}

This paper investigated the students' preparedness towards writing a bachelor thesis. Because of a small selection it is hard to generalize, but it can be used as an indicator.

- The students were prepared when writing their bachelor thesis based on the results from the survey. When asked before they started their project the students had high expectations to their abilities regarding academic writing, referencing, ability to work in groups, knowledge about the subject in question and the report template. Approximately two months later the students still rated their abilities high, indicating that the expectations and reality align. This is accomplished by having a clear and distinct focus on this throughout the study programme.

- The students had a high score on motivation. They have frequent meetings with their supervisors during their project period which also results in continuous feedback. Feedback have been proved to help the students on their learning outcome and to motivate the students in their work. The high scores on motivation both before and after supervision indicates that the students' expectations were met.

- Having a workshop, lecture, and peer review in the beginning of the students' bachelor project does not seem to have the hoped-for effect. The results from the second survey did not show a significant difference from the first survey, indicating little or no difference in knowledge on the topics covered. The students did however rate the peer review session useful. However, there has not been done any investigation on the consequences of not offering this to the students, meaning that the peer review, lecture and workshop might have a preventive, and thus positive, effect.

\section{REFERENCES}

[1] Imel S. "Collaborative Learning in Adult Education. ERIC Digest No. 113," 1991.

[2] Burdett J. "Making groups work: University students' perceptions," International Education Journal, vol. 4, no. 3, pp. 177-191, 2003.

[3] Hattie J., Biggs J. and Purdie N. "Effects of learning skills interventions on student learning: A meta-analysis," Review of educational research, vol. 66, no. 2, pp. 99-136, 1996.

[4] Hattie J. and Jaeger R. "Assessment and classroom learning: A deductive approach," Assessment in Education: principles, policy \& practice, vol. 5, no. 1, pp. 111-122, 1998.

[5] Black P. and Wiliam D. "Assessment and classroom learning. Assessment in Education, 5 (1), 7 74," Google Scholar Google Scholar Cross Ref Cross Ref, 1998.

[6] Lovitts B. E. Making the implicit explicit: Creating performance expectations for the dissertation. Stylus Publishing, LLC., 2007.

[7] Lundgren S. M. and Halvarsson M. "Students' expectations, concerns and comprehensions when writing theses as part of their nursing education," Nurse Education Today, vol. 29, no. 5, pp. 527$532,2009$.

[8] Mulder R. A., Pearce J. M. and Baik C. "Peer review in higher education: Student perceptions before and after participation," Active Learning in Higher Education, vol. 15, no. 2, pp. 157-171, 2014, doi: 10.1177/1469787414527391.

[9] Gielen S., Tops L., Dochy F., Onghena P. and Smeets S. "A comparative study of peer and teacher feedback and of various peer feedback forms in a secondary school writing curriculum," British Educational Research Journal, vol. 36, no. 1, pp. 143-162, 2010, doi: 10.1080/01411920902894070.

[10] Forskrift om rammeplan for ingeniørutdanning, 2018. 
[11] Heimdal A., Thorstensen R. T. and Svennevig P. "INVESTIGATIONS ON THE USE OF STUDENT PEER REVIEW TO IMPROVE SUPERVISION OF CAPSTONE COURSES IN THE CIVIL ENGINEERING EDUCATION," in DS 104: Proceedings of the 22nd International Conference on Engineering and Product Design Education (E\&PDE 2020), VIA Design, VIA University in Herning, Denmark. 10th-11th September 2020, 2020.

[12] Almlie G. S. "Akademisk fagskriving på ingeniørstudiet," Nordic Journal of Information Literacy in Higher Education, vol. 12, no. 2, pp. 4-19, 2020. 